\title{
TRANSTORNO DE DÉFICIT DE ATENÇÃO/HIPERATIVIDADE NA INTERFACE SAÚDE E EDUCAÇÃO: UMA EXPERIÊNCIA COM EDUCADORES
}

\author{
Tássia Lorene de Carvalho ${ }^{1}$ \\ Suellen Ibrahim Peron ${ }^{2}$ \\ Soraya da Silva Sena ${ }^{3}$ \\ Luciana Karine de Souza ${ }^{4}$
}

Resumo: Neste artigo relata-se a experiência resultante da realização de um curso de extensão oferecido a professores de Ensino Médio que acompanharam seus estudantes na visita à Mostra das Profissões/2008, organizada pela Universidade Federal de Minas Gerais. O curso teve por objetivo oferecer um espaço de reflexão crítica e cientificamente fundamentada para os professores sobre o Transtorno de Déficit de Atenção e Hiperatividade e suas implicações para a saúde e a educação. São traçadas também considerações acerca dos desafios enfrentados e das possibilidades de melhoria para próximas edições do curso. Entende-se que a articulação entre pesquisa e extensão encontra espaço privilegiado em oportunidades como a relatada, com trocas ímpares entre educadores e pesquisadores que compartilham objetivos na busca da aproximação entre saúde e educação.

Palavras-chave: transtorno; TDAH; escola; desenvolvimento. 


\section{Introdução}

Na presente oportunidade é relatada a experiência resultante da realização de um curso de extensão oferecido a professores de Ensino Médio que acompanharam seus estudantes na visita à Mostra das Profissões/2008, organizada pela Universidade Federal de Minas Gerais. A Mostra das Profissões da UFMG tem como finalidade principal informar ao aluno do Ensino Médio sobre as diferentes opções de cursos de graduação oferecidos pela UFMG. Dessa forma, a Universidade procura contribuir para uma escolha profissional conscienciosa a partir do acesso livre e organizado às informações sobre os cursos. Além disso, o evento visa a ampliar a visão e perspectivas dos alunos e professores em relação à Universidade e aos diferentes campos profissionais existentes. Durante o evento, são ofertadas atividades diversas, como palestras sobre os cursos e o mercado de trabalho, bem como salas interativas com estudantes universitários e profissionais já graduados. Para os professores que acompanham os estudantes na Mostra são disponibilizados cursos de curta duração (até quatro horas) ministrados por professores e pesquisadores da UFMG, das várias áreas do conhecimento, tratando de temas de interesse para esse público (<http://www2.ufmg.br/mostra09>).

\section{Uma breve descrição do TDAH: focalizando o contexto escolar}

É notável o aumento, nos últimos anos, de crianças diagnosticadas como portadoras de TDAH. Em resposta a esse quadro, é igualmente crescente a demanda de educadores sobre esclarecimentos acerca do transtorno. Assim, a oferta de um curso que tratasse do tema de forma direta e que possibilitasse a reflexão crítica e cientificamente fundamentada proporcionaria aos professores conhecimento básico sobre o transtorno e motivação por estudos complementares. Além disso, outra expectativa que embasou a oferta do curso foi o benefício esperado no que diz respeito às relações entre educador e portador, assim como ao papel do educador como mediador melhor capacitado a facilitar as interações da criança com TDAH com outras crianças, professores e seus pais. 
Apesar de não haver consenso nos manuais de diagnóstico de doenças mentais sobre a caracterização precisa do TDAH, a definição mais utilizada por profissionais da saúde tem sido a descrita conforme os critérios diagnósticos do DSM-IV-TR (APA, 2002; Rotta, 2006 ): consiste em uma síndrome neurocomportamental, caracterizada especialmente pela prevalência de hiperatividade-impulsividade e/ou desatenção. Dessa forma, conforme a predominância dos sintomas, o transtorno pode se apresentar segundo três tipos: predominantemente desatento, predominantemente hiperativo, ou misto (APA, 2002).

O diagnóstico de TDAH em crianças e adolescentes deve ser feito através da observação dos sintomas. Sendo estes em número superior a seis, conforme listagem contida no DSM-IV-TR, devem estar presentes antes dos sete anos de idade e em mais de dois contextos (isto é, em casa e na escola, por exemplo). Ademais, é importante atentar para as comorbidades, sendo as mais comuns Transtorno de Aprendizagem, Transtorno Desafiador-Opositor (TDO), Transtorno de Personalidade Anti-Social e a Dislexia (MARTINS, TRAMONTINA \& ROHDE, 2003; ROHDE et al., 1999). O tratamento mais indicado para o TDAH é uma combinação de procedimentos. No caso, o mais utilizado tem sido a psicoterapia aliada ao tratamento com fármacos. No Brasil, o uso da abordagem psicoterapêutica na modalidade cognitivo-comportamental como tratamento psicossocial no TDAH tem se mostrado bastante promissor (DUCHESNE \& MATTOS, 2001; SENA \& DINIZ NETO, 2005; TEIXEIRA, 2006), auxiliando especialmente na aprendizagem para o autocontrole, modulação do comportamento social e regulação da atenção (TEIXEIRA, 2006).

Os sintomas indicativos do TDAH são mais observados em crianças no contexto escolar. Os desafios que o TDAH traz a todos os envolvidos na comunidade escolar são apresentados no trabalho de Reppold e Luz. As atividades que envolvem a necessidade de seguir regras e limites e/ou de sustentar a atenção durante determinado tempo fornecem oportunidade para a identificação dos estudantes que podem estar com sintomas do TDAH. As crianças do tipo hiperativo, em especial, são comumente descritas como agitadas e referidas como "capetinhas" ou como se tivessem "ligadas em uma bateria", 
perturbando a classe inteira e sobrecarregando o educador. Em entrevista com educadores da região Sul do Brasil, Reppold e Luz constataram um desconhecimento, por parte dos professores, sobre o TDAH e como lidar com os portadores, assim como percepções destes últimos como intencionalmente agressivos, provocadores e maleducados. Acima de tudo, as autoras descobriram que, na experiência de mais de $65 \%$ dos educadores entrevistados, as crianças com TDAH na escola apresentavam dificuldades de integração social, especificamente rejeição.

O trabalho de Reppold e Luz (2007) se encerra com recomendações pontuais para educadores sobre como interagir com a criança com TDAH, especialmente mediante o uso de frases curtas e claras na comunicação com ela. Já Rohde, Dorneles e Costa (2006) destacam a criação de rotinas que auxiliam a criança a compreender o que é esperado dela em termos de desempenho; dividir as tarefas em distintas etapas e iniciar as aulas com as atividades que requerem maior atenção. Mais recentemente, Mesquita (2009) concluiu sua dissertação de mestrado no tema, discutindo de forma interessante e envolvente os desafios e dificuldades na relação entre os educadores e o TDAH.

É notável a preocupação que profissionais da saúde vêm demonstrando com relação ao indivíduo com TDAH. Tanto na clínica como na pesquisa, há um movimento dedicado a realmente investigar o transtorno e possibilitar a melhoria da qualidade de vida do portador. Paralelamente, pesquisadores e clínicos vêm gradativamente procurando se aproximar dos dois principais contextos de desenvolvimento infantil - a família e a escola -, cientes de que sem a participação de pais e de educadores o tratamento do indivíduo fica restrito a poucas ações. Nessa direção, destaca-se o atual investimento na formação de educadores capazes tanto de colaborar na identificação de sintomas de hiperatividade e/ou de desatenção, como de participarem ativamente da melhoria da qualidade de vida da criança com TDAH por meio de atividades direcionadas a ela e colaborando na mediação de suas interações com colegas e pais. Como exemplo, o livreto de orientação a professores, de Rosário, Reis, Shayer, Gattás, Godinho e Nunes (s/ d) traz de forma concisa e clara informações importantes e orientações 
diretas sobre como o professor pode colaborar sem deixar de cumprir com seu papel de educador.

Além do treinamento de professores, os pais igualmente vêm sendo convocados a atentar para as especificidades que o(a) filho(a) portador(a) demanda. O Programa de Treinamento de Pais (PTP) tem potencial para ser eficaz em um bom número de casos, incluindo comunidades carentes de regiões urbanas marginalizadas do Brasil (PINHEIRO, HAASE, DEL PRETTE, AMARANTE \& DEL PRETTE, 2006). O PTP é destinado a pais de crianças com problemas de comportamento, seja por hiperatividade ou comportamento desafiador opositor (HAASE, GAMA, GUIMARÃES \& DINIZ, 1998). Para Pinheiro e cols. (2006), boa parte dos comportamentos inadequados de crianças com distúrbios externalizantes manifesta-se e é mantida pelos déficits apresentados pelos próprios pais em habilidades sociais e no monitoramento do comportamento dos filhos, tornando imprescindível o treinamento nessas habilidades. Considerando que os problemas secundários ao TDAH - baixa auto-estima, baixo repertório de habilidades sociais, problemas escolares, abusos de substâncias psicoativas e distúrbios de conduta - retroalimentam os sintomas nucleares, e que há causas e consequências daqueles nos ambientes familiar e escolar do portador, pode-se apontar o PTP como indicação básica no tratamento do TDAH (PINHEIRO, CAMARGOS JR. \& HAASE, 2005).

\section{Curso: "Transtorno de Déficit de Atenção/Hiperatividade - Relacionando Saúde e Educação"}

Participaram do curso 19 professores do Ensino Fundamental e Médio, previamente inscritos no site da UFMG, provenientes de diversas escolas de Minas Gerais que se deslocaram ao Campus Pampulha para acompanhar os estudantes na "Mostra das Profissões 2008". Os professores foram recebidos no início do curso com um hand-out contendo informações básicas sobre o TDAH, com indicação de bibliografia, além de cópia das lâminas de power-point que seriam apresentadas. Estruturalmente, o curso intercalava conhecimento técnico-científico e dinâmica em grupo para facilitar sua compreensão. 
Dessa forma, visava-se não apenas a transmissão do conhecimento sobre o transtorno, mas também a estimulação da criatividade e da reflexão crítica que motivassem tanto o interesse em compreender o TDAH como a busca posterior do conhecimento mais aprofundado sobre a criança por ele acometida.

O curso iniciou com a conceituação do TDAH mediante uma dinâmica na qual os professores puderam diferenciar as informações prévias corretas das informações oriundas de mitos sobre o transtorno. O objetivo da dinâmica era esclarecer a diferença entre o TDAH e outras comorbidades infantis comuns. Para isso, foram afixadas em uma parede da sala faixas com os seguintes títulos: TDAH, Depressão e Transtorno de Aprendizagem. Foram entregues aos participantes pequenos papéis que continham descrições de sintomas de cada um dos transtornos citados. O professor deveria anexar o sintoma descrito no respectivo cartaz do transtorno. Em seguida, cada sintoma foi discutido e, aqueles que foram colocados no cartaz errado, foram recolocados e discutidos, num movimento de caracterizar e diferenciar o TDAH dos demais transtornos.

Após a realização da primeira dinâmica recémdescrita, foram apresentadas aos professores as informações sobre o TDAH, dividida em duas partes distintas, separadas por uma segunda dinâmica que será descrita mais adiante. Na primeira parte da apresentação oral, tratou-se da definição do transtorno, tipos, critérios diagnósticos, origem, prevalência, comorbidades, tratamento e mitos sobre o TDAH. Foi especialmente interessante a apresentação dos mitos, entre os quais o de que o TDAH não é real, é um modismo, que é culpa dos pais e que desaparece com o tempo. Esses e outros mitos suscitaram várias manifestações dos professores que, no cotidiano escolar, tomam contato com esses conteúdos na comunicação com pais e colegas de trabalho. É interessante mencionar os tópicos mais comentados pelos educadores a partir da atividade realizada, como o contraste entre o TDAH e uma educação parental sem limites, e o papel dos profissionais da saúde no contato com professores para substituir mitos por conhecimento científico e informação útil.

Feito um intervalo, o curso foi retomado com uma dramatização conduzida pelas duas primeiras autoras desse texto. O objetivo foi de 
representar uma sessão de psicoterapia com uma menina portadora de TDAH em comorbidade com TDO (Transtorno DesafiadorOpositor). A dramatização desenvolveu-se conforme segue:

Uma psicóloga está sentada à espera de sua paciente, portadora de TDAH, que, ao chegar, bate fortemente na porta em dois momentos, demonstrando grande impaciência para ser atendida. A profissional abre a porta e a criança joga sobre ela um pequeno relatório enviado pela professora e vai logo utilizar os brinquedos disponíveis na sala. A menina espalha todos os brinquedos no chão e brinca com vários ao mesmo tempo. A psicoterapeuta tenta interagir com a cliente, que de início não se mostra responsiva, mas depois permite que brinquem juntas de 'fazer chá'. Durante a brincadeira, a menina joga vários objetos na psicóloga que, no espírito da brincadeira, diz que foi queimada pelo 'chá quente'. A menina, sem qualquer tolerância, responde que não se tratava de 'chá', e sim peças de brinquedo. A profissional então se afasta da cliente, senta-se novamente em sua cadeira e lê o relatório enviado pela escola. A menina brinca por alguns instantes sozinha, mas logo desvia sua atenção para a psicóloga, senta-se em uma cadeira próxima a ela e fica observando-a ler. A criança grita duas vezes, até que a psicóloga relembre-a de que ali não se pode gritar, apenas nos intervalos de aula ou em brincadeiras. Sem parecer dar atenção ao que foi dito, a menina pergunta o que a profissional está lendo. Essa responde que a leitura é do relatório enviado pela escola, e que nesse relatório está escrito que ela bateu nos coleguinhas. A criança senta-se imediatamente ao chão, começa a mexer em pecinhas isoladas dos brinquedos e convida a psicóloga para brincar. Revela que briga com os colegas porque estes não lhes dão atenção e não brincam com ela, deixando-a sozinha nos recreios. Enquanto brincam a conversa continua: a psicóloga pergunta à criança do que ela gostaria de brincar com os colegas. A menina, sem responder, desrespeita as regras da brincadeira em andamento. A profissional adverte a portadora, e diz que, como as regras do jogo não estavam sendo seguidas, ela também iria agir de forma diferente do que diz as regras. A reação da criança é dizer que a psicóloga está mentindo e que nenhuma regra foi quebrada. É perguntado à criança se ela gostaria de brincar com quem nela batesse. A criança pensa por instantes e começa a guardar alguns 
brinquedos de forma desorganizada, mandando a psicóloga arrumar os demais e dizendo que era hora de ir-se. A profissional não a obedece, afirmando que só guardaria os brinquedos após a menina fazer a parte dela. Antes de terminar, a paciente sai da sala rapidamente, dizendo que a mãe já esperava por ela. Fim da encenação.

A encenação foi acompanhada de um debate conjunto entre organizadoras e professores sobre as atitudes das crianças portadoras de TDAH demonstradas na dramatização. Na pauta da discussão estiveram sempre presentes situações semelhantes vividas pelos professores no ambiente escolar, assim como a maneira que eles poderiam lidar com os comportamentos em pauta. A título de exemplo, surgiram questões sobre a conciliação da atenção do educador ao portador de TDAH e aos demais estudantes da sala de aula; a forma como as tarefas deveriam ser comunicadas para conseguir motivar o portador a realizá-las; e a problemática do TDAH em meninas e de como passa despercebido na escola. Tais questões demonstram uma preocupação dos educadores em contribuir para um melhor desempenho e aprendizagem dos alunos que enfrentam dificuldades provenientes do transtorno aqui discutido.

Seguindo a pauta do curso, a terceira etapa compreendeu uma exposição complementar com outras informações sobre o TDAH. Nessa segunda apresentação foram tratados os temas das relações de pares e de amizade da criança com TDAH, cuidados pedagógicos importantes e objetivos do tratamento multidisciplinar. Novo espaço para debate, dúvidas, troca de idéias e de experiências foi aberto aos professores, após o que o curso foi encerrado. Entre os principais tópicos abordados na discussão, ressaltam-se as dificuldades dos professores em lidar com alunos portadores de TDAH, principalmente considerando-se o grande número de crianças em cada turma. Duas importantes questões levantadas pelos participantes foram sobre a avaliação do aluno diagnosticado e a função do educador em situações de negligência familiar, no que tange às manifestações comportamentais do TDAH. 


\section{Considerações sobre a experiência relatada: unindo saúde e educação}

A experiência proporcionada pela condução do curso relatado reforçou a importância e a pertinência de aproximações entre pesquisadores e educadores. Em especial, é necessária atenção redobrada diante de desafios como o diagnóstico do TDAH e suas implicações para a aprendizagem e o desenvolvimento infantil como um todo, desde a esfera cognitiva até a social, como se buscou ressaltar na oportunidade.

Como ponto forte do curso realizado pode-se apontar a estrutura escolhida, que buscou intercalar a apresentação de conteúdos sobre o TDAH com atividades práticas e dramatizações, envolvendo mais diretamente os participantes e motivando-os à reflexão crítica cientificamente embasada. A atividade que envolveu o esclarecimento sobre os sintomas do TDAH aliada à comparação com comorbidades mais comuns também pareceu suscitar maior responsividade e envolvimento dos participantes nos debates do curso. Outro ponto interessante, e que foi fundamental no planejamento e execução do curso com a estrutura oferecida, foi o envolvimento direto e orientado com as duas estudantes de graduação e a de pós-graduação, esta última tendo, inclusive, contribuído não apenas com seus estudos de Mestrado sobre o tema do TDAH, mas também com sua experiência profissional no atendimento a crianças com esse transtorno.

Uma das limitações que podem ser apontadas na atividade descrita é a da duração. Para futuras edições seria importante duplicar a duração do curso e, ampliando-se a parceria com outros setores da Universidade, fornecer certificados aos educadores que cumprissem com um mínimo de presença no curso. Também o número de vagas pode ser aumentado, por exemplo, para 50, inclusive abrangendo educadores que não estejam envolvidos em acompanhar seus estudantes na Mostra das Profissões da UFMG, mas que teriam interesse em participar de um curso de extensão voltado à sua prática profissional com crianças portadoras de TDAH.

No âmbito da universidade, pode-se identificar o potencial desse tipo de curso para agregar distintas habilidades do ambiente acadêmico. 
A promoção da relação ensino-pesquisa-extensão destacou-se na presente atividade, demonstrando ser possível agrupar harmonicamente essas três esferas de atuação do docente universitário. Ademais, a participação dos estudantes de graduação é igualmente recompensadora, na medida em que a eles é proporcionada a prática integrada dos ensinamentos aproveitados no curso, o envolvimento com a iniciação científica e o contato com a comunidade em geral pela ação de extensão. Em especial, graduandos não apenas de psicologia, mas de outras áreas como a educação, a medicina, a educação física e a fonoaudiologia podem participar de atividades como a relatada, promovendo um exercício de prática multiprofissional e interdisciplinar.

\section{Notas}

${ }^{1}$ Graduanda do Curso de Psicologia da Universidade Federal de Minas Gerais.

${ }^{2}$ Graduanda do Curso de Psicologia da Universidade Federal de Minas Gerais.

${ }^{3}$ Psicóloga, Mestre em Psicologia do Desenvolvimento pelo PPG-Psicologia da Universidade Federal de Minas Gerais.

${ }^{4}$ Psicóloga, Mestre em Psicologia, Doutora em Psicologia do Desenvolvimento pela UFRGS. Docente no Depto. de Psicologia da Universidade Federal de Minas Gerais. Endereço para contato: UFMG-FAFICH-Depto. De Psicologia, Profa. Luciana K. De Souza, Av. Antônio Carlos, 6627, sala F-4050, Campus Pampulha, CEP:31.310-530, Belo Horizonte, MG. E-mail: lucianak@fafich.ufmg.br. As autoras agradecem à PróReitoria de Graduação da UFMG na pessoa de Danielle Zarate e à Profa. Dra. Delba Barros, Coordenadora do Curso de Psicologia da UFMG.

\section{Referências}

AMERICAN PSYCHIATRIC ASSOCIATION. DSM-IV-TR - Manual Diagnóstico e Estatístico de Transtornos Mentais. 4. ed. Porto Alegre-RS: Artmed, 2002.

DUCHESNE, Mônica; MATTOS, Paulo. Tratamento do transtorno do déficit de atenção com hiperatividade e impulsividade. In: RANGÉ, B. (Org.). Psicoterapias cognitivo-comportamentais: um diálogo com a psiquiatria. Porto Alegre-S: Artmed, 2001. p. 400-412.

HAASE, Vitor et al. Intervenções cognitivo-comportamentais para os distúrbios externalizantes. Cadernos de Psicologia.vol.8, Belo Horizonte-MG, p. 203-218, 1998. 
HAASE, Vitor; PINHEIRO, Maria Isabel Santos; CAMARGOS JR, Walter. Treinamento de pais. In: HOUNIE, A. G.; CAMARGOS JR., W. (Orgs.). Manual clínico de déficit de atenção/hiperatividade. Nova Lima-MG: Info, 2005. p. 942-969.

MARTINS, Sílvia; TRAMONTINA, Silzá; ROHDE, Luís Augusto. Integrando o processo diagnóstico. In: ROHDE, L. A.; MATTOS, P. (Orgs.). Princípios e práticas em transtorno de déficit de atenção/hiperatividade. Porto AlegreRS: Artmed, 2003. p. 151-160.

MESQUITA, Raquel C. De. A implicação do educador diante do TDAH: repetição do discurso médico ou construção de uma resposta educacional? Dissertação (Mestrado em Conhecimento e Inclusão Social em Educação). Universidade Federal de Minas Gerais, Belo Horizonte, 2009.

PINHEIRO, Maria Isabel Santos; CAMARGOS Jr., Walter; HAASE, Vitor. Treinamento de pais. In: HOUNIE, A. G.; CAMARGOS Jr., W. (Orgs.). Manual clínico do transtorno de déficit de atenção/hiperatividade. Belo HorizonteMG: Editora Info, 2005. p. $942-966$

PINHEIRO, Maria Isabel Santos et al. Treinamento de habilidades sociais educativas para pais de crianças com problemas de comportamento. Psicologia: reflexão e crítica, 19, 407-414, 2006.

REPPOLD, Caroline; LUZ, Simone. A compreensão do professor sobre o Transtorno de déficit de atenção e hiperatividade e o impacto sobre o trabalho docente em escola pública. In: HUTZ, C. (Org.). Prevenção e intervenção em situações de risco e vulnerabilidade. São Paulo-SP: Casa do Psicólogo, 2007. p. 77-98.

ROHDE, Luís Augusto et al. ADHD in a school sample of Brazilian adolescents: a study of prevalence, comorbid conditions and impairments. Journal of the American Academy of Child and Adolescent Psychiatry, 38(6), 716-22, 1999.

ROHDE, Luís Augusto; DORNELES, Beatriz Vargas; COSTA, Adriana. Intervenções escolares no transtorno de déficit de atenção/hiperatividade. In: ROTTA, N.; OHLWEILER, L.; RIESGO, R. (Orgs.). Transtornos da aprendizagem: abordagem neurobiológica e multidisciplinar. Porto AlegreRS: Artmed, 2006. p. 365-374. 
ROSÁRIO, Maria Conceição do et al. Transtorno do déficit de atenção e hiperatividade (TDAH): uma conversa com os educadores. São Paulo-SP; Salvador-BA: UNIFESP/UFBA, [s/d].

ROTTA, Newra. Transtorno da atenção: aspectos clínicos. In: ROTTA, N.; OHLWEILER, L.; RIESGO, R. (Orgs.). Transtornos da aprendizagem: abordagem neurobiológica e multidisciplinar. Porto Alegre-RS: Artmed, 2006. p. 301-13.

SENA, Simone da Silva; DINIZ-NETO, Orestes. Distraído e a 1000 por hora: perguntas e respostas sobre transtorno do déficit de atenção e hiperatividade. Belo Horizonte-MG: Anome Livros, 2005. 175 p.

TEIXEIRA, Gustavo. Transtornos comportamentais na infância e adolescência. Rio de Janeiro-RJ: Rubio, 2006.

\section{Abstract: \\ Disorder Attention Deficit / Hyperactivity Disorder in the interface health and education: an experience with educators.}

This article reports the experience from a short-term course taught to highschool teachers that were accompanying their students during the Mostra das Profissoes/2008 held by federal University of Minas Gerais, Brazil. The course aimed at offering an opportunity to discuss, critically and with scientific basis, the ADHD and its health and educational implications. Challenges and improvements are discussed in the sight of future editions of the course. The union between research and its contributions to community needs find fine in opportunities like the one described on this article, with unique trade of expertise between researchers and educationalists that share the goal of associating health and education.

Keywords: : Disorder. ADHD. School. Development.

Recebido em setembro de 2009.

Aceito em dezembro de 2009. 